Interested parties are invited to submit proposals or views to the working party, and are asked to send them to the secretary, Joint Working Party on Sixth Form Curriculum, the Schools Council, 160 Great Portland Street, London WI.

\section{Better Materials}

The Explosives Research and Development Establishment (ERDE) of the Ministry of Technology-at Waltham Abbey, Essex, last week held its first open days since it was established in 1945. One of the aims of the open days seems to have been to acquaint industry with the work in progress at ERDE on the development of polymers and the design of high strength composite materials. The 500 acre site at Waltham Abbey has a long association with explosives going back more than four conturies, first as a private gunpowder works and later as the Royal Gunpowder Factory. It has a network of canals which at one time used to be the means of transport within the site. The facilities at ERDE include remote handling equipment for the testing of now explosives and the

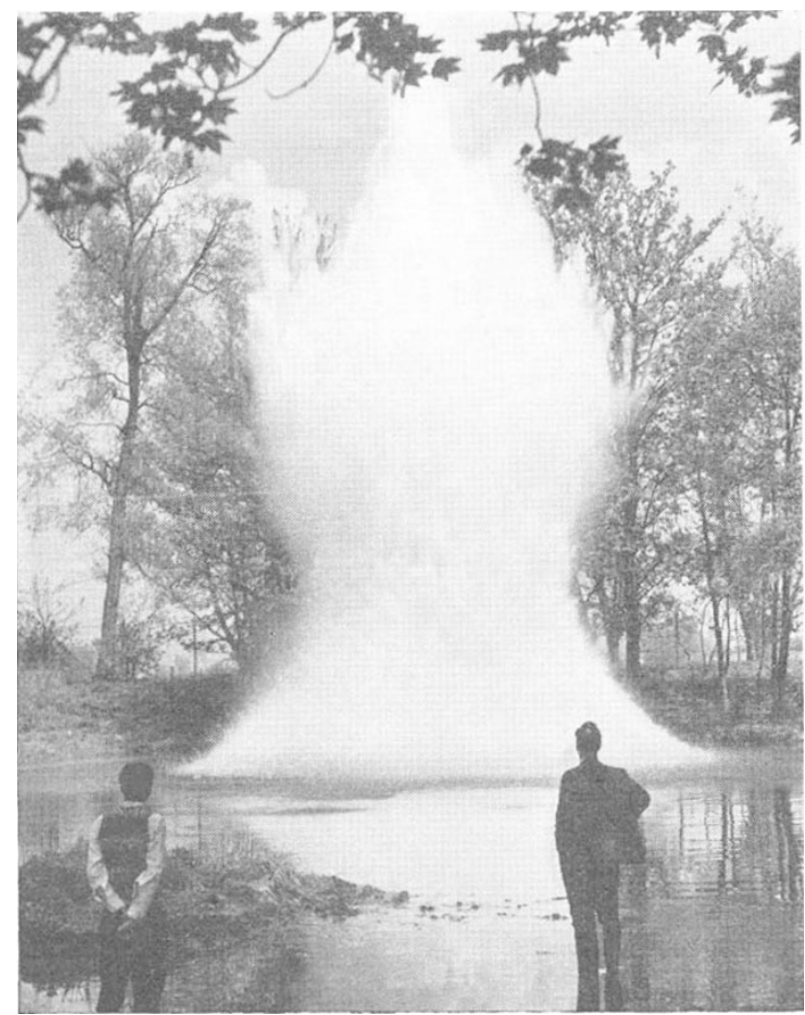

Testing underwater explosives at the Explosives Research and Development Establishment.

large-scale processing of rocket propellants. Although explosives and propellants still form the mainstay of the work at Waltham Abbey, about 30 per cent of the establishment's effort is now devoted to materials research. ERDE seems to have become particularly adept at developing materials of high strength by adding reinforcing fibres. Some of the new composite materials have properties which may make them suitable for applications in the aviation industry.

One of the lines of research under way is the investigation of thermoplastics containing various fibrous fillers as alternatives to glass-fibre. A number of fibres have been tried, including asbestos, carbon and whiskers of silicon carbide, in a range of thermoplastics. Asbestos and silicon carbide fibres have been particularly successful-silicon carbide giving the better properties but at a higher cost than asbestos.

Work on the strengthening of thermoplastics is leading on to the improvement of the properties of metals by the addition of reinforcing fibres. The addition of whiskers of silicon carbide to aluminium is producing the strength and high temperature properties of titanium at only half the weight. So far, reinforced aluminium has only been produced on a pilot plant basis, but it looks as if the chief difficulties -the manufacture of whiskers of silicon carbide and their alignment in the metal-have in principle at least been overcome. Now that the aviation industry is beginning to need the properties of titanium in the construction of supersonic aircraft, the prospects of aluminium reinforced by fibres look attractive. It is materials such as these which are likely to make weight problems such as those the American supersonic transport is facing at present a less important factor in the design of future generations of aircraft.

Apart from this work on composites, the materials sections at ERDE are also working on the improvement of polymers for applications such as flexible fuel tanks, dracones, arrester tapes for aircraft and hovercraft skirts. Here the problems are the degradation of the material by the effects of heat, light and fucls. By investigating the way in which the polymers break down under these influences, ways of modifying the polymers to make them more permanent are being developed.

\section{Analysis of MEDLARS}

A FULL-SCALE evaluation of the performance of MEDLARS (Medical Literature Analysis and Retrieval System) by the National Library of Medicine in the United States shows that the system is operating on average at about 58 per cent recall and 50 per cent precision, that is to say, it retrieves 58 per cent of relevant documents in response to a specific request, at the expense of having 50 per cent irrelevant documents retrieved at the same time. The results of the analysis, the first large-scale evaluation of a major operating information system, have recently been published in a report from the library (Evaluation of the MEDLARS Demand Search Service, US Dept of Health, Education and Welfare, 1968). Unfortunately the report is written in such a way that for a nonspecialist in information retrieval systems it is difficult to tell the wood from the trees. This is a pity, because the user of the service ought to be as aware of the results as the MEDLARS specialist, and indeed one of the rather cryptically written recommendations is that there is a great need for improvement in MEDILARS "at the interface between user and system".

The test programme was conducted impartially by a specially recruited "information systems evaluator", with the help of an advisory committee appointed by the director of the National Library of Medicine. An analysis was made of 300 actual requests made to the system in 1966 and 1967. It concentrated on the evaluation of the demand search function of MED. LARS, that is, the behaviour of retrospective literature 